\title{
त्र \\ Strength of the Bond of Structural Steel S235JR to Bronze SAE660 Produced by Casting in Pre-Mold
}

\author{
M. Zaheri ${ }^{a}$, S.E. Vahdat ${ }^{\text {b, * }}$ \\ ${ }^{a}$ Department of Engineering, Bandar Abbas Branch, Islamic Azad University, Bandar Abbas, Iran \\ ${ }^{\mathrm{b}}$ Department of Engineering, Ayatollah Amoli Branch, Islamic Azad University, Amol, Iran \\ *Corresponding author. E-mail address: e.vahdat@iauamol.ac.ir
}

Received 29.03.2017; accepted in revised form 22.05.2017

\begin{abstract}
Different methods are used for production of bronze bearings. In terms of technical specifications, the success of each of these methods depends on the bond's strength and in terms of economic, the production method is important. In this study, the aim is to study the strength and microstructure of steel-bronze thrust bearing bond that has been produced through the casting using pre-mold. In this study, in order to bond, the raw metals are chemically washed with sulfuric acid solution for five minutes at first. Then, the molten bronze SAE660 is cast in a structural steel S235JR pre-mold. The bond's strength has been measured using the shear test three times; the measurement of bond's length has been done using field emission scanning electron microscope (FESEM). The results indicate that the strength of the bond is at least $94.8 \mathrm{MPa}$ and bond's length is 0.45 micrometers. Therefore, this method was successful for trust bearing application.
\end{abstract}

Keywords: Bond's length, Trust bearing, Weld

\section{Introduction}

In ancient ages, Egyptians move huge rocks with moving on wooden timber and they were soaked them in water or oil for ease of movement. Then, the use of wooden axle, wheels and bearings in carriage and the use of animal fat to lubricate them became common. Discovery of Babbitt alloy in 1839 by Isaac Babbitt and its use in manufacturing metal bearings of steam engines and then building bronze bearings have been other developments in the progress of bearings. Production of sliding bearings in the rail transportation industry in 1949 , production of roller bearings in the early 1960s and eventually production of magnetic in 1980 s and bearings have be other developments in the emergence of bearings [1].
Bearing is a piece between at least two pieces that allows relatively easy rotational or linear movement. In the other hand, each piece that reduces friction between contact surfaces is called bearing. Two important task of bearing in devices with moving parts are first, keeping axis so that prevents its loosening too much and second, preventing axle lateral movement so that prevents collision of moving parts and they became fix. Another way to categorize bearings is in term of the type of force acting on it including radial force, thrust force and radial-thrust force. In addition, bearings in terms of the internal structure are divided into three groups including sliding contact bearing, rolling bearing and magnetic bearing [2].

If the thrust force is acted on the piece, radial bearings cannot prevent thrust from moving. Therefore, thrust bearing must be used. A thrust bearing is a bearing that bear thrust load during working [1]. Therefore, the force at the bond of layers is high and 
therefore the quality of the bond of these layers must be accountable to the force.

Thrust bearing tolerates the total weight of rotating components (for example in diesel engines, the total weight of the crankshaft, connecting rods, pistons, related screws and so on) and trust pressure. Thrust pressure of thrust block is transferred to bearing pieces. These pieces are placed on spring plates and finally on the thrust bracket. Oil needed to lubricate and cool the bearings are supplied by pumping action (without pump) of radial holes in thrust block during the rotation of this part [1]. Therefore, the quality of the bond of these metals is very important because if the bond of these metal layers is weak, they will be separated each other.

To achieve acceptable bond by plating method sing brazing, four important factors including the quality of the bond, the quality of filler metals, uniform heat and appropriate reactant are involved [3]. Thus, in this study, degreasing is first done by hot dipping. Then, oxidizing the surface is done by sanding. After that, degreasing is done through the electrical method. Finally, surface is activated using acid washing to ensure good adhesion.

Cladding using brazing method is for coating components for creating intermediate layer [4]. In this method, pieces are coated by a filler metal with a melting point lower than the base metal. In cladding process that used to coat pieces, fillers in the form of wire, straps, profiles, powder or even molten are used [5]. In this study, the bronze filler in the form of respected profile is used because the bond was not a simple shape.

A method for making a steel-bronze bearing is horizontal centrifugal casting method. In this method, the length of the bond has been reported up to 2.4 micrometers $[6,7]$. The techniques used in that research is expensive. Moreover in that study, bond's strength has not been reported. However, in this study a much simpler and less expensive method with good bond's strength is introduced.

Another way to build a thrust steel-bronze bearing is cladding through brazing. Brazing is performed for bonding of metals and alloys using filler metals with the melting point lower than melting point of base metals. In brazing, the surfaces of pieces are heated until melting temperature of the bearing metal. The main difference between brazing and welding is that in brazing, the base metal is not melted, but in the welding, the base metal is melted. In the process of hard brazing, filler metal is melted with a melting point higher than $450^{\circ} \mathrm{C}$ that has a temperature lower than the melting point of the base metal's bond, while in the process of soft brazing, filler metal is melted with a melting point less than or equal to $450^{\circ} \mathrm{C}$ that has a temperature less than the melting point of the base metal at the bond [8]. Therefore, cladding bronze on steel with melting point of about $800^{\circ} \mathrm{C}$ is hard brazing.

On the other hand, the brazing procedure has been used for manufacturing CK10 steel bearings with ASTM B2 Babbitt layer with a bond's length of 6.6 micrometers [7]. This approach has been successful for Babbitt bearings. For this reason, in the current study, this method has been used for the manufacture of bearing bronze.

In addition, brazing method is used for manufacturing steel bearing CK15 with C93200 bronze layer. In that study, the length of the bond has been reported inconsiderable (in the scale of one micrometer). Therefore, in that study, this method was not successful for manufacturing a bronze bearing. The reason of being unsuccessful has been attributed to relatively low temperatures and relatively short time [9]. For this reason, in this study, the casting time has been increased to double time and casting temperature has been increased by $50^{\circ} \mathrm{C}$. In addition, the production has been done with more control.

In this research, the aim is to study strength and length of the bond between bronze SAE660 and the structural steel S235JR in thrust bearing produced by casting in the pre-mold.

\section{Materials and Method}

In this study, to evaluate the mechanical properties of steelbronze thrust bearing, which is produced by casting in the premold, bond's strength and bond's length of bronze SAE660 with thickness of $5 \mathrm{~mm}$ to the structural steel S235JR with a thickness of $10 \mathrm{~mm}$ are investigated. For this purpose, the shear test (according to Figure 1a) device and FESEM TESCAN MIRA III available in the laboratory, approved by the Standardization Administration of Iran were used.

As shown in Table 1, the chemical composition of the thrust bearing metal that was a piece of structural steel S235JR with a diameter of $100 \mathrm{~mm}$, it has been determined using ARL device and listed according to ASTM E415-15 standard [10]. Depth of bronze profile was $5 \mathrm{~mm}$ and diameter of profile was $90 \mathrm{~mm}$. Premold thicknesses was $15 \mathrm{~mm}$, bronze thickness was $5 \mathrm{~mm}$ and the used flux was made of zinc chloride, ammonium chloride, sodium chloride and tin powder.

To ensure accuracy, all the experiments of this study were conducted in Razi Metallurgical Research Center (RMRC). Moreover, to ensure precision, all the experiments were repeated at least three times.

A 6mm-thick structural steel S235JR sheet was purchased from Sepahan Steel Company. The chemical composition of the sheet was checked using ARL quant-meter device, as shown in Table 1.

Table 1.

Chemical composition of structural steel S235JR

\begin{tabular}{ccccccccccc}
\hline Element & $\mathrm{Fe}$ & $\mathrm{C}$ & $\mathrm{Mn}$ & $\mathrm{Si}$ & $\mathrm{Cr}$ & $\mathrm{Cu}$ & $\mathrm{Al}$ & $\mathrm{Ni}$ & $\mathrm{S}$ & $\mathrm{P}$ \\
\hline $\mathrm{Wt} \%$ & Balance & 0.15 & 0.47 & 0.24 & 0.06 & 0.06 & 0.047 & 0.02 & 0.005 & 0.019 \\
\hline
\end{tabular}

Bronze alloy SAE660 as filler in the form of a profile with thickness $5 \mathrm{~mm}$ and diameter of $90 \mathrm{~mm}$ is machined so that it has no impurity. Chemical compound of using alloy in this process, SAE660 bronze based on standard DIN EN 15079-15 [11] with the help of WAS machine are determined and listed in Table 2.

Table 2.

Chemical composition of bronze SAE660

\begin{tabular}{ccccccccc}
\hline Element & $\mathrm{Cu}$ & $\mathrm{Sn}$ & $\mathrm{Pb}$ & $\mathrm{Zn}$ & $\mathrm{Fe}$ & $\mathrm{Ni}$ & $\mathrm{S}$ & $\mathrm{Ag}$ \\
\hline $\mathrm{Wt} \%$ & Balance & 7.0 & 9.0 & 2.1 & 0.29 & 0.53 & 0.014 & 0.01 \\
\hline
\end{tabular}

Before bronze cladding, steel cleaning is performed as following:

1. Mechanical cleaning is performed by steel brush.

2. Components will be floated in sulfuric acid solution for 5 minutes. 
3. Components are washed with methanol alcohol (ethyl) for 10 minutes.

4. Components are covered by hand method with flask (Zinc chloride, Ammonium chloride, Sodium Chloride, Tin powder).

5. Filler metal (bronze) is washed and cleaned with acid solution for 10 minutes.

For performing cladding, at first bronze filler is placed inside profile and then it will be heated until alloy is melted. After melting, torch will be remained on for six minutes. Then cladding component is cooled until room temperature. In Figure $1 \mathrm{~b}$, final product is showed.

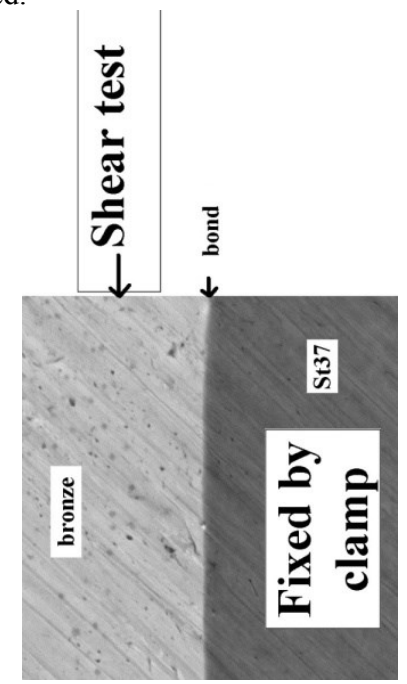

a)

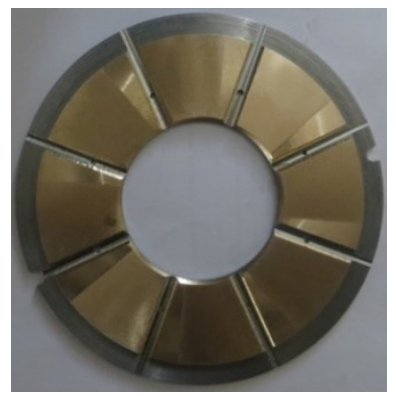

b)

Fig. 1. a) Shear test procedure, b) Final product of bronze trust bearing

\section{Results and Discussion}

Around the bond place, three white, black and grey phases are observed. To study these phases based on Figure 2, at first ray is set on a phase with minimum size equals 5 micrometers. Then energy dispersive spectroscopy (EDS) is prepared. To insure the accuracy of results, at least the experiments are repeated 3 times.

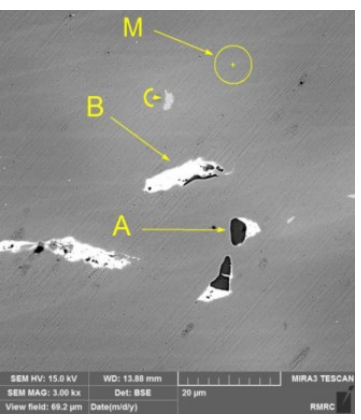

Fig. 2. Image of $\mathrm{ZnS}$ (black phase A), pure lead (white phase B), intermetallic compound $\mathrm{Cu}_{4} \mathrm{Sn}$ (grey phase $\mathrm{C}$ ) and Matrix (M)

Based on EDS and its quantitative values in Figure 3, black phase is MS impurity in which $\mathrm{M}$ is included into vast quantities of Zinc (40.41 atomic percent), copper (4.40 atomic percent) and also small amounts of iron (1.37 atomic percent), Lead (1.12 atomic percent) and Tin ( 0.63 atomic percent).

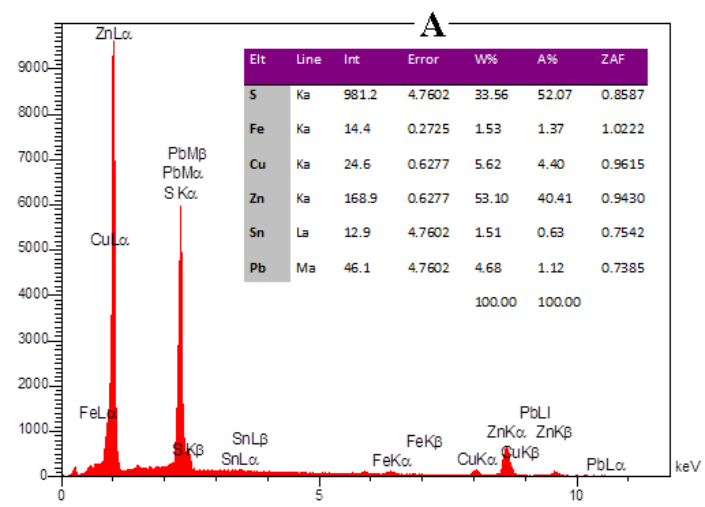

Fig. 3. EDS of MS impurity (black phase of A)

Based on EDS and its quantitative values in Figure 4, white phase is almost pure lead (94.57 weight percent) and small values of Zinc as solid solution ( 0.73 weight percent) and iron is as impurity (0.21 weight percent) because due to phase figure of Lead-Copper in Figure 5, the combination of Lead-Copper or solid solution are not formed, but copper peak (4.50 weight percent) is related to matrix.

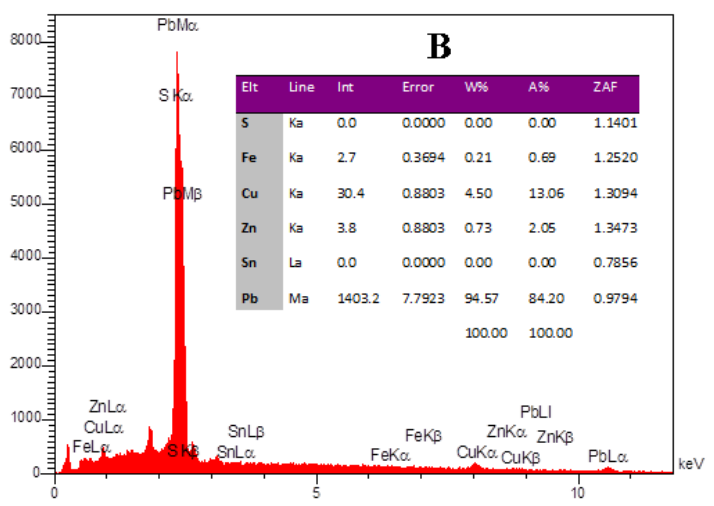

Fig. 4. EDS of $\mathrm{Pb}$ (white phase of $\mathrm{B}$ ) 


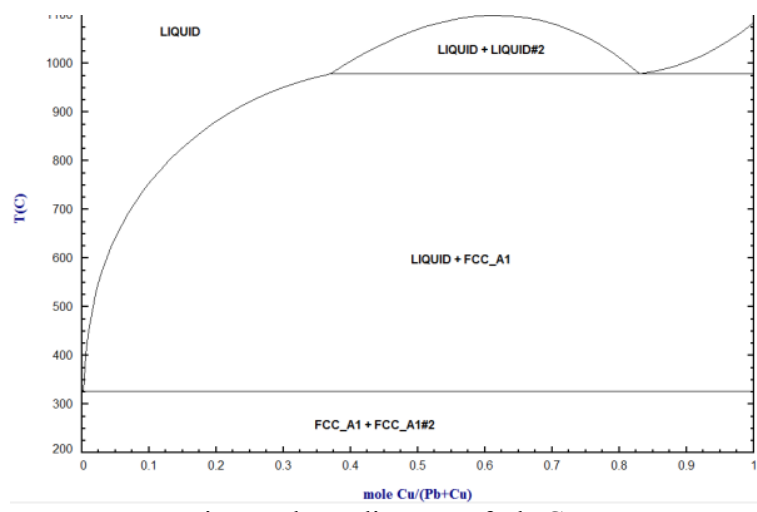

Fig. 5. Phase diagram of $\mathrm{Pb}-\mathrm{Cu}$

Based on EDS and its quantitative values in Figure 6 and due to phase diagram of Copper-Tin and the position of this alloy in this diagram (Figure 7), grey phase is intermetallic compound $\mathrm{Cu}_{4} \mathrm{Sn}$, because it is included 78.10 atomic percent of Copper and 19.92 atomic percent of Tin.

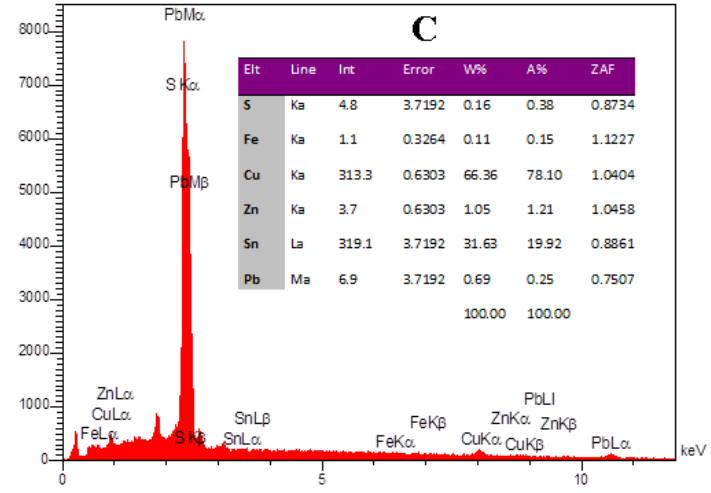

Fig. 6. EDS of intermatallic compound $\mathrm{Cu}_{4} \mathrm{Sn}$ (grey phase of $\mathrm{C}$ )

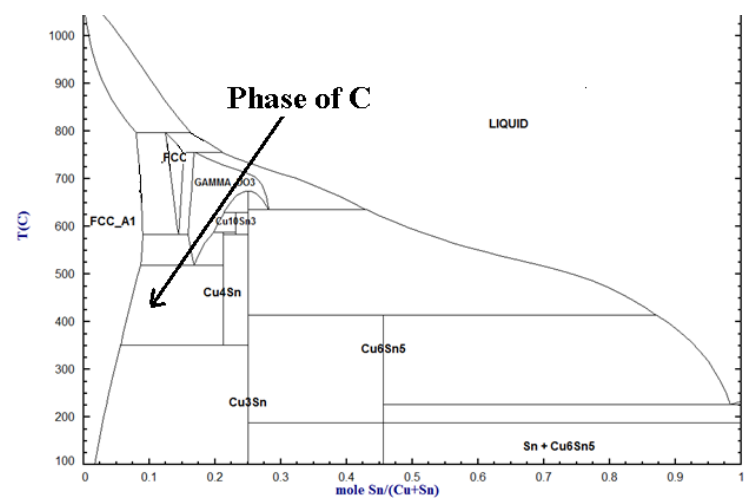

Fig. 7. Phase diagram of $\mathrm{Cu}-\mathrm{Sn}$

Based on EDS and its quantitative values in Figure 8, chemical composition of matrix is included into 86.30 weight percent of Copper, 9.08 weight percent of Tin, 3.37 weight percent of Zinc and small values of Lead (0.52 weight percent), Sulfur (0.44 weight percent) and Iron impurities ( 0.29 weight percent).

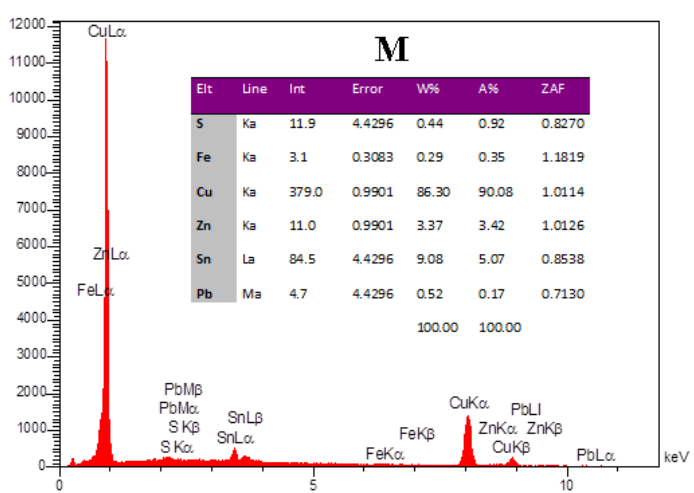

Fig. 8. EDS of Matrix

The presence of sulfur element in amount of 0.014 weight percent and zinc as alloy element in amount of 2.1 weight percent causes the formation of $\mathrm{ZnS}$ impurity. For this purpose, controlling chemical composition of bronze with the minimum amount of sulfur is necessary. On the other hand, the presence of $\mathrm{Cu}_{4} \mathrm{Sn}$ intermetallic compound causes increasing hardness and the strength of bronze matrix.

In Figure 9, line scanning was performed in 30 points of bond place of bronze-steel in the scale of 1 micron. For better analysis, in Table 3 the points are brought on this Figure. Based on Table 3, the influence of copper and tin elements is recognizable in the points 14 to 16 . Because from bronze to steel side, the value of copper element gradually decreases from 88.34 weight percent to 2.45 weight percent and the value of lead element gradually decreases from 3.44 to 0.89 weight percent and consequently, it will added to the value of iron element while through this distance, the value of zinc element is not changed. Hence the length of the bond is 0.45 micrometer.

Table 3.

Quantitative results of 30 points of Line scan of bronze-steel interface

\begin{tabular}{|c|c|c|c|c|c|c|c|}
\hline oint & lement & & ity & Error & $\mathrm{Wt} \%$ & $\mathrm{~A} \%$ & ZAF \\
\hline \multirow{4}{*}{$1-13$} & $\mathrm{Fe}$ & \multirow{3}{*}{$\mathrm{Ka}$} & 24.3 & 0.3149 & 3.54 & 4.13 & 1.1935 \\
\hline & $\mathrm{Cu}$ & & 252.4 & 0.7331 & 88.34 & 90.61 & 1.0057 \\
\hline & $\mathrm{Zn}$ & & 5.9 & 0.7331 & 2.79 & 2.78 & 1.0070 \\
\hline & $\mathrm{Sn}$ & $\mathrm{La}$ & 20.7 & .7148 & 3.44 & 1.89 & 0.8466 \\
\hline \multirow{4}{*}{14} & $\mathrm{Fe}$ & \multirow{3}{*}{$\mathrm{Ka}$} & 55.8 & 0.4409 & 8.57 & 9.80 & 1.1795 \\
\hline & $\mathrm{Cu}$ & & 229.0 & 0.7067 & 84.30 & 84.74 & 0.9968 \\
\hline & $\mathrm{Zn}$ & & 8.4 & 0.7067 & 4.17 & 4.08 & 0.9979 \\
\hline & $\mathrm{Sn}$ & $\mathrm{La}$ & 11.9 & 0.4548 & 2.05 & 1.10 & 0.8463 \\
\hline \multirow{4}{*}{15} & $\mathrm{Fe}$ & \multirow{3}{*}{$a$} & 345.1 & 1.0418 & 61.18 & 64.57 & 1.0479 \\
\hline & $\mathrm{Cu}$ & & 87.9 & 0.7203 & 35.13 & 32.59 & 0.9425 \\
\hline & $\mathrm{Zn}$ & & 4.7 & 0.7203 & 2.50 & 2.25 & 0.9493 \\
\hline & $\mathrm{Sn}$ & $I_{I}$ & 6.8 & 0.1874 & 1.19 & 0.59 & 0.8581 \\
\hline \multirow{4}{*}{16} & $\mathrm{Fe}$ & \multirow{3}{*}{$\mathrm{Ka}$} & 563.7 & 0.6107 & 88.64 & 90.82 & 1.0123 \\
\hline & $\mathrm{Cu}$ & & 19.7 & 0.6411 & 6.91 & 6.22 & 0.9196 \\
\hline & $\mathrm{Zn}$ & & 5.6 & 0.6411 & 2.61 & 2.29 & 0.9294 \\
\hline & $\mathrm{Sn}$ & Ja & 5.4 & 0.5690 & 0.81 & 0.39 & 0.8643 \\
\hline \multirow{4}{*}{$1-3$} & $\mathrm{Fe}$ & \multirow{3}{*}{$\mathrm{Ka}$} & 561.4 & 0.6834 & 92.93 & 95.14 & 1.0082 \\
\hline & $\mathrm{Cu}$ & & 6.6 & 0.6444 & 2.45 & 2.20 & 0.9174 \\
\hline & $\mathrm{Zn}$ & & 4.1 & 0.6444 & 2.01 & 1.76 & 0.9278 \\
\hline & Sn & La & 5.7 & 0.6514 & 0.89 & 0.43 & 0.864 \\
\hline
\end{tabular}




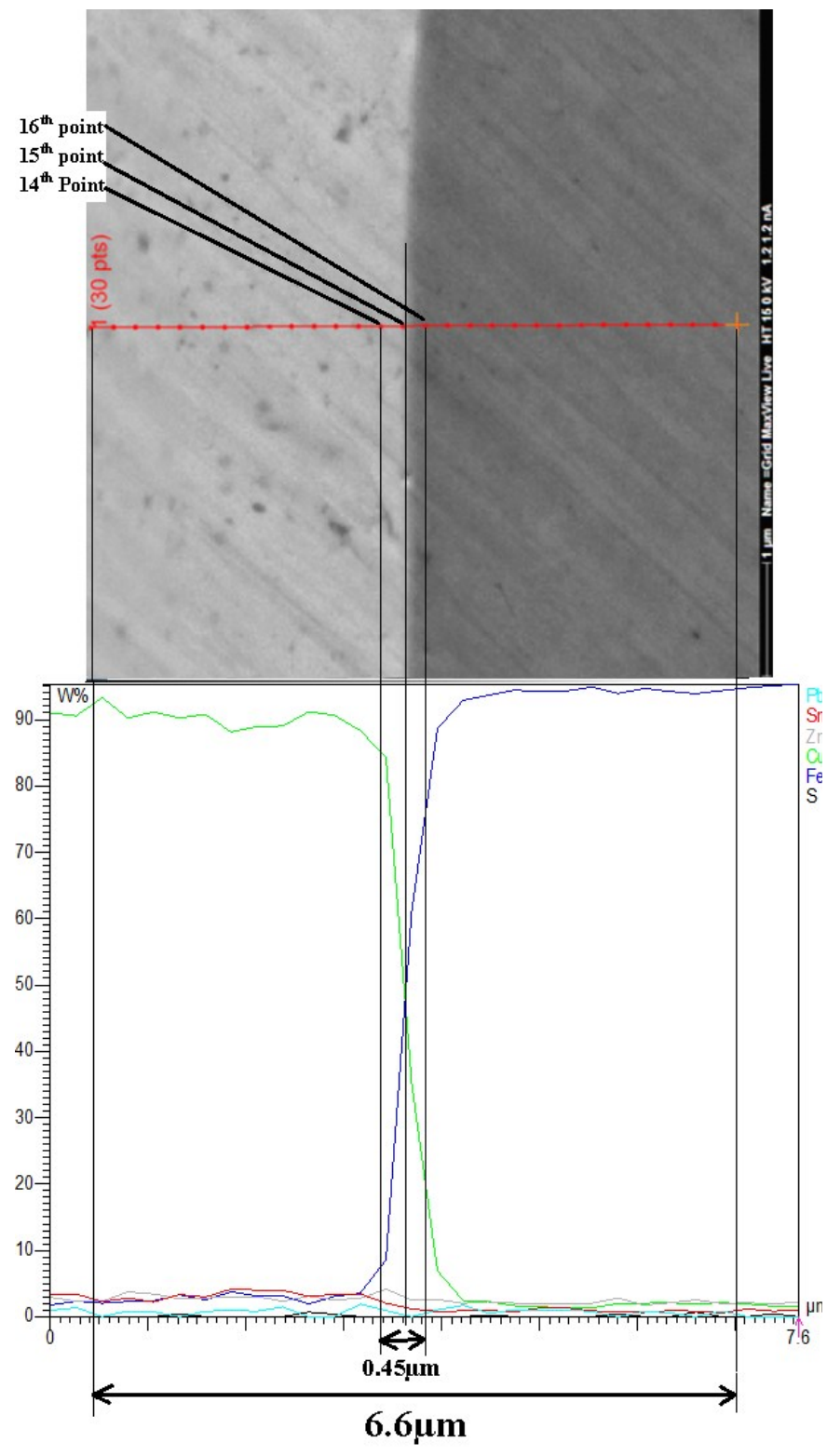

Fig. 9. Line scan of bronze-steel interface

In this study, this method was successful because in comparison to previous research [9], the time of the process is increased from three minutes to six minutes and consequently the temperature of process is increased about $50^{\circ} \mathrm{C}$. In Table 4, bond's strength of structural steel S235JR to SAE660 bronze in this study is listed. It is observed that the least strength of the bond is $94.8 \mathrm{MPa}$.

Table 4.

Bond's strength of structural steelS235JR-SAE660bronze

\begin{tabular}{cccc}
\hline No. & Contact area & Force & Bond's strength \\
\hline 1 & $38.84 \mathrm{~mm}^{2}$ & $3681 \mathrm{~N}$ & $105.6 \mathrm{MPa}$ \\
\hline 2 & $31.31 \mathrm{~mm}^{2}$ & $3361 \mathrm{~N}$ & $107.3 \mathrm{MPa}$ \\
\hline 3 & $37.44 \mathrm{~mm}^{2}$ & $3550 \mathrm{~N}$ & $94.8 \mathrm{MPa}$ \\
\hline
\end{tabular}

Yield strength of SAE660 bronze is about $138 \mathrm{MPa}$ and its tensile strength is about $241 \mathrm{MPa}$. In addition, yield strength of structural steel S235JR is about $290 \mathrm{MPa}$ and its tensile strength is about $440 \mathrm{MPa}$. In present study based on the minimum bond's strength of bronze-steel equals to $94.8 \mathrm{MPa}$, this strength is acceptable for bearing applications. Because the minimum bond's strength (94.8 $\mathrm{MPa})$ is less than yield strength of bearing metal $(138 \mathrm{MPa})$ and more than the half of its yield strength $(138 \div 2=69 \mathrm{MPa})$. Hence bond's strength is not very low, but before bearing metal is turned to permanent deformation, it will be separated from the steel. In bearings, above feature is useful, because permanent deformation in bearing metal in movable series of crankshaft and connecting rod (even about micrometer) causes lack of lubrication thin film and also in cause's great damage $[1,12]$.

\section{Conclusion}

In this study, the aim is to study the strength and microstructure of steel-bronze thrust bearing bond that has been produced through the casting using pre-mold. In order to bond, the raw metals are chemically washed at first by using sulfuric acid solution for five minutes. After that, it washed by using methanol alcohol for ten minutes. Then, the molten bronze SAE660 is cast in a structural steel S235JR pre-mold holding for six minutes. The bond's strength has been measured using the shear test 3 times; the measurement of bond's length has been done using FESEM. Results showed that the strength of the bond is at least $94.8 \mathrm{MPa}$ and the length of the bond is 0.45 micrometer. This bond's strength is acceptable for bearing applications. Because the minimum bond's strength $(94.8 \mathrm{MPa})$ is less than yield strength of bearing metal $(138 \mathrm{MPa})$ and more than the half of its yield strength $(138 \div 2=69 \mathrm{MPa})$.

\section{References}

[1] Challen, B., Baranescu, R. (1999). Diesel Engine Reference Book: Butterworth-Heinemann.

[2] Vahdat, S.E. (2011). Approperiate materials for diesel engines. Tehran: Chortkeh (in persian).

[3] ASM. Chapter 2. (1992). Copper Base Bearing Materials. In: William AG, ed. Tribology Series: Elsevier: 46-68.

[4] Xiong, J-t, Xie, Q., Li, J-1., Zhang, F-s. \& Huang, W-d. (2012). Diffusion Bonding of Stainless Steel to Copper with Tin Bronze and Gold Interlayers. Journal of Materials Engineering and Performance. 21(1), 33-7.

[5] Weman K. (2012) 16 - Soldering and brazing. Welding Processes Handbook (Second edition): Woodhead Publishing: 167-74.

[6] Soflaei H, Vahdat SE. (2016). Microstructure Study of Diffusion Bonding of Centrifuged Structural Steel-Bronze. Archives of Foundry Engineering. 16(2), 99-106.

[7] Zand, A., Kalvand, H. \& Vahdat, S.E. (2016). Microstructure study for determining the diffusion depth of Babbitt ASTM B2 on steel CK25 coated with soft soldering process. Manufacturing and production magazine. 34:9 (in persian). 
[8] ASM Handbook (1993). Volume 6: Welding, Brazing, and Soldering: ASM International.

[9] Zand, A., Kalvand, H. \& Vahdat, S.E. (2016). Bond improvement of C52100 bronze thrust bearing poured into pre-mould CK20 steel by using MIG welding. Manufacturing and production magazine. 35:10 (in persian).

[10] ASTM-E415. (2015). Standard Test Method for Analysis of Carbon and Low-Alloy Steel by Spark Atomic Emission Spectrometry. USA: ASTM: 11.
[11] DIN-EN-15079. (2015). Copper and copper alloys. Analysis by spark optical emission spectrometry (S-OES). Europian Union: DIN English :24.

[12] Hogan, T.A. (1985). Acquisition and Review of Diesel Generator Testing Data. IEEE Transactions on Nuclear Science. 32(1):1122-4. 